\title{
Voices of Young Mothers on Relational Issues Leading to Out-of-Wedlock Pregnancy and its Protective Measures: A Qualitative Exploration
}

\author{
Hizlinda $\mathrm{T}^{\mathrm{a}}$, Noriah $\mathrm{Ml}^{\mathrm{b}}$, Suzaily $\mathrm{W}^{\mathrm{c}^{*}}$, Khairani $\mathrm{O}^{\mathrm{d}}$, Harlina Halizah $\mathrm{S}^{\mathrm{e}}$, Susan Mooi Koon $\mathrm{T}^{\mathrm{f}}$, \\ Aishah $\mathrm{A}^{\mathrm{c}}$, Noorlaili $\mathrm{T}^{\mathrm{a}}$ \\ ${ }^{a}$ Department of Family Medicine, Universiti Kebangsaan Malaysia Medical Centre, 56000 Cheras, Kuala Lumpur Malaysia \\ ${ }^{\mathrm{b}}$ Pusat PERMATApintar Negara, Universiti Kebangsaan Malaysia, 43600 Bangi, Selangor \\ 'Department of Psychiatry, Universiti Kebangsaan Malaysia Medical Centre, 56000 Cheras, Kuala Lumpur Malaysia \\ ${ }^{d}$ International Medical School, Management and Science University, 40100 Shah Alam, Selangor \\ e Department of Obstetrics and Gynaecology, Universiti Kebangsaan Malaysia Medical Centre, 56000 Cheras, Kuala Lumpur Malaysia \\ ${ }^{f}$ Park City Medical Center, 52200 Kuala Lumpur, Malaysia
}

\section{ABSTRACT}

INTRODUCTION: Adolescents learn through experimenting and interactions with others. Experimenting romance and sexuality issues if not properly guided, can result in an out-of-wedlock unplanned pregnancy. This study aims to explore factors leading to out-of-wedlock pregnancy among pregnant teenagers and factors that may prevent such occurrence. MATERIALS AND METHODS: Two in-depth interviews (IDI) and two focus group discussions (FGD) were conducted in this qualitative study. The study involved 22 participants from a local governmental body shelter home in Peninsular Malaysia. Interviews were audio-recorded and transcribed verbatim. Thematic analysis was used for data analysis. RESULTS: Three salient relationship themes that led to teenage pregnancy were i) an enjoyable relationship with peers, ii) poor family relationship, and iii) intimate relationship with boyfriends. Some of the proposed ways that may protect teenagers from pregnancy include i) careful selection of friends, ii) controlling the desire in risky experimentation, and iii) wiser use of smartphones or/and social media. CONCLUSION: Relational issues with parents, peers and boyfriends are important factors as it could lead to out-of -wedlock pregnancy among adolescents and youths. It is also necessary for the current educational system to emphasize on building positive relationships with peers, being more assertive, and the safe use of social media among youths.

KEYWORDS: Teen pregnancy, relation, adolescent

\section{INTRODUCTION}

Pregnancy before the age of 20 has been a major public health concern worldwide. It has detrimental effects not just on the teenager's physical and mental health but on her social life too. According to the Malaysian National Obstetric Registry (NOR), teenage pregnancy accounted

Corresponding Author:

Assoc. Prof. Dr. Suzaily Wahab

Department of Psychiatry,

Faculty of Medicine,

Universiti Kebangsaan Malaysia Medical Centre, Jalan

Yaacob Latif, Bandar Tun Razak, 56000 Cheras,

Kuala Lumpur, Malaysia,

Tel No : +03-91456142

E-mail : suzailywhb@yahoo.com for $5 \%$ of the total deliveries since 2010 , which is lower than the worldwide estimate of $11 \% .1,2$ Only $16 \%$ of the pregnant teenagers registered with NOR between 2010 and 2012 were unmarried. ${ }^{2}$ However, the real prevalence of premarital teenage pregnancy may be higher as a result of an increasing prevalence of adolescent premarital sexual activity, which is mostly unprotected. ${ }^{2-5}$

Multiple factors have been attributed to premarital sexual activity among teenagers in Malaysia which may lead to pregnancy including the influence of individual, family and peers. School-going teenagers' involvement 
with high-risk behaviours such as smoking, alcohol drinking and drug use, significantly increase their odds of engaging in premarital sexual activity, whereas having a good family and peer relationships indicated by strong parental connectedness and bonding as well as having close friends and peer support were the protective factors. ${ }^{3}$

Previous local studies also emphasized the linkage between unhealthy relationships with parents, family and peers with teenagers engaging in high-risk behaviours and premarital sexual activity. ${ }^{6-8}$ The teenagers studied indicated that family conflict, growing up in poverty, having poor relationships with parents (which they described as distant and uncaring), having less family time together and poor communication, lack of supervision and monitoring, lack of assertiveness, lack of commitment in carrying out religious practices, as well as poor social support, led them to seek attention, happiness and love from peers and boyfriends. ${ }^{6-8}$ Spending more time socializing in this manner led the teenagers to be easily influenced in engaging with highrisk behaviours such as substance abuse, pornography and sexual activity. ${ }^{6-8}$ These multiple interrelated factors are best captured through qualitative studies, allowing in -depth exploration of the dynamic relationships.

However, the available qualitative studies examining factors of out-of-wedlock pregnancy among teenagers are limited and were only carried out in certain parts of Malaysia. Therefore, this study sought to explore the experiences of teenage mothers residing in a shelter home in the southern part of Peninsular Malaysia. Amongst its aims were to identify relational factors that could have led them to out-of-wedlock pregnancy as well as measures that could protect the teenagers from being pregnant.

\section{MATERIALS AND METHODS}

This qualitative study was carried out at an institution in the Southern part of Peninsular Malaysia that provided shelter, formal education and rehabilitation to out-ofwedlock teenage mothers under the organisation of the state religious body. Twenty-two Malay teenage mothers aged between 14 and 20 years old who were pregnant or had recently given birth were included in this study. The inclusion criteria were out-of-wedlock pregnancy that IMJM Volume 20 No.1, Jan 2021 occurred before the teenage mothers reached 20 years old. The participants were originally from various states in Malaysia but were residing in the institution during data collection.

Two in-depth interviews (IDI) and two focus group (FGD) discussions were concurrently carried out by five researchers, who were trained in qualitative research. A semi-structured interview protocol was used to guide researchers in exploring the main topics during the interviews which include: i) factors that led to teenage pregnancy in general, ii) factors that led to the participant's pregnancy, and iii) factors that could protect teenagers from being pregnant. The interviews were carried out in Bahasa Malaysia and lasted between 60 to 110 minutes, whereby the conversations were recorded using digital audio recorders.

The recorded interviews were transcribed into text by a research assistant and examined for its accuracy by a researcher. The researcher subsequently performed a thematic analysis on all the transcripts using Nvivo 9.

Permission to carry out the study was obtained from the institutional research ethical committee, the Social Welfare Department of Malaysia, the state Islamic department and the head of the institution. For the participants aged below 18 years old, written or verbal consents were attained from the protectors or legal guardians of the teenagers (as according to the Child Act 2001) and their parents via mail or telephone. All participants provided written consents to participate in this study.

Confidentiality was maintained by keeping the data in a safe place throughout the project which could only be accessed by the researchers. In addition, the participants' anonymity was maintained throughout the analysis process by replacing the participants' original names with pseudo-names. Debriefing was also performed to ensure the participants were not psychologically affected as a result of exploring their past experiences.

\section{RESULTS}

The participants in this study described their relational experiences that led to unwanted pregnancy during 
adolescence as being very challenging. These relational experiences were developed with their peers, family and partners (boyfriends).

\section{Relational Experiences with Peers}

The participants told stories about their relational experiences with their peers which included: (a) having fun with random activities without parental control, (b) activities to overcome stress and boredom, (c) high-risk activities, and (d) experimenting with sex.

\section{Having fun with random activities without parental control}

Many participants posited that life before pregnancy was focused on having fun with their peers. This could clearly be heard as the pervasive theme in the focus group interviews. Many participants suggested that they went out for various fun activities to socialise including those that appeared to be innocent activities such as eating, shopping, watching movies and swimming without much parental control.

"...I enjoyed myself too much. Too much freedom (without parental control) ... roamed around to all types of places (eating place, shopping mall, movie theatre etc").

\section{Activities to overcome stress and boredom}

The participants claimed that they came from homes with a negative home environment where parents and family members were constantly arguing and being critical resulting in these adolescents distancing themselves from the parents and family members.

Many posited that they also felt stressed by school because they do not have any passion for academic work. They were more interested in arts, photography, fashion, culinary activities or sports that were lacking in the school curriculum.

"I love clothes... like fashion. My ambition is to become a photographer", "I only went to school when there were sports. I love track events (running), burdle events", and "T'm more interested in things like... cooking... and food catering".
They went out to have fun as they claimed that spending time with their peers could relieve their boredom and stress due to negative home environment as described above as well as their consistent dislike of school. Some played truant to be with their boyfriends and finally ended up having unprotected sex at a cheap motel or at the boyfriend's house.

\section{High-risk activities leading to sexual involvement}

The participants also admitted they spent time doing high-risk activities such as smoking, drinking alcohol, using illicit drugs, clubbing, motorbike racing, and watching pornography due to curiosity and peer pressure. The activities were regarded as normal and acceptable by their community of teenagers.

"I started going out wildly with friends... regardless of boys or girls. Started going to places which are not meaningful... like clubbing. I like spending my time... jamming and hanging out with friends. Then I started... smoking... and I like wearing sexy clothing." 'I swallowed the 'five-five' pill. He(boyfriend) was the one who gave it to me".

These high-risk activities help the participants developed an intimate relationship with their partners, and create an opportunity for sexual relationships leading to unprotected sexual intercourse.

\section{Experimenting with sex}

Many of the participants narrated their stories on the role of peers in encouraging them to experiment with sex. One of the participants posited that her friends and her exchange stories and information on their sexual activities. She felt encouraged to try after listening to their stories. Many participants narrated the involvement of pornography leading them to experimentation with sex. She suggested that, "I will try and experiment with sex after watching an act in the video or internet (through YouTube)..." and she loves to try something new when experimenting with sex. Inevitably, they felt aroused and experimented with the act that they had watched. The participants also shared their personal experiences of sexual experimentation, which normally start with petting, cuddling and light kisses, with no intention for sex. However, over time 
the light petting led to them having sex with their partners.

\section{Relational Issue with Family}

Having poor relationships with parents had led some of the participants to seek attention and relational satisfaction outside their homes, particularly with friends from both genders. They described their parent-child relationship as very loose and meaningless. Their parents were busy working most of the time and since there were no family activities that bonded them together, they felt neglected and unloved. Due to the lack of parental commitment, many turned to secret activities with their boyfriends to satisfy their need for adventure.

"They never took me out to the waterfall. They were busy. My boyfriend was the one who brought me there. But when I went there with my boyfriend, a lot of other things happened too".

Aside from the lack of family involvement, some participants suggested that they were involved in promiscuity because of poor monitoring from parents. One of the participants narrated that she left home and stayed with her boyfriend, and her parents never asked about her activities.

Some of the participants also described experiencing family disharmony and constant miscommunication. Their parents were always in a conflict which caused tension among the children. The constant parental nagging, arguing, fighting, controlling and scolding turned them into a 'time bomb about to explode'. These situations triggered feelings of frustration, boredom and anger, and the consistent need for some freedom.

"Don't over control.... It means do not be too angry over things that we want to do for no reason... give us a bit of freedom".

Other than that, the participants also attribute the lack of religious guidance from parents as a contributing factor for a sexual relationship.

\section{Relational Issues with Boyfriends}

The majority of the participants had a steady relationship with their boyfriend based on perceived love and trust. One participant elucidated such an intimate relationship in which she had consensual sex. However, she felt betrayed because her boyfriend left her after the sexual encounters. On a rebound, she went into another relationship but was raped by the new boyfriend. Because these participants were young, they went into a relationship hoping for emotional and monetary support from their boyfriends even though they knew that their boyfriends were involved in highrisk behaviours. Some participants were very much aware of their boyfriends' high-risk behaviour, yet they still continued the relationship.

"I knew he plays around with girls and took many types of drugs. He even impregnated one girl and irresponsibly left the relationship. I was attracted to him because he was very popular in racing and I felt proud to be with him (even when I knew he was on drugs).

Some participants also reported that their boyfriend persuaded them to run away from home, take alcohol and have unprotected sex even when they were only 15 years old.

During exploration of factors that could protect teenagers from being pregnant, the teenagers provided strategies reflecting their experiences which include the use of contraception and other socially-related preventive measures. Participants had some knowledge about the various contraceptive methods as an approach to prevent pregnancy, which included the use of condoms, contraceptive pills, emergency contraception, intrauterine contraceptive device and contraceptive injection. However, they ignored the importance of having protected sex because this was never their priority.

"I know about the contraception but I never used it"; "I never used condom... and I feel that even when I used it, I can still get pregnant...so why bother".

On the other hand, some of the participants posited that they did use contraception, yet they still end up pregnant. The question to ponder here is, whether they have the knowledge on how to use the contraception correctly.

The socially-related preventive measures suggested by 
the participants include positive relationship with friends, having inner strengths by being more assertive, and selective use of the social media (Table 1). Being careful in choosing friends and having self-control along with positive engagement when with peers were emphasized by them. Assertiveness in declining boyfriend's invitation to be alone with him could prevent sexual encounters as posited by a participant. Some of them believed that indiscriminate use of social media could lead to befriending those with bad influences and watching pornography, thus it should be avoided.

\section{DISCUSSION}

The findings of our study suggested that the participants who spent more time with friends either through loitering, smoking cigarettes, drinking alcohol, using drugs, and watching pornography have been shown to increase teenagers' risks in engaging with premarital sexual activity. Similar results have also been found in other studies.3,6,9-12 These activities provided more opportunities to socialise with the opposite gender as well as those with high-risk behaviours. As a result, they were more likely to experiment with high-risk behaviours practised by their peers and adopt a liberal attitude towards dating, physical intimacy and premarital sexual activities.7,13,14 Their freedom in socialising with friends, probably as a consequence of poor parental monitoring and supervision as described by some of the participants, was found to increase their odds for premarital sex.7,15 It appeared that teenagers in this study were directly or indirectly influenced by their peers through persuasion. Furthermore, going out with friends gave them the opportunity to engage in group dating, which might be considered acceptable by them as they were not actually courting with their boyfriends alone in secluded places. ${ }^{14}$ These findings highlight the strong peer influence during adolescence. ${ }^{16}$ Friends tend to provide emotional support more than their parents, ${ }^{17}$ and teenagers particularly females, are more susceptible to negative peer pressure. ${ }^{10}$ Nevertheless, some studies showed contradictory findings whereby having high peer attachment protected teenagers from sexual activity, highlighting the importance of the positive influence of close friends. 3,10 Thus, it is important to guide teenagers on choosing friends who can provide a more positive influence. The participants also claimed socializing with friends enabled them to relieve their stress and boredom. A local study among male teenage inmates in a welfare institution in Klang Valley also documented the use of sex as a way to relieve stress. ${ }^{13}$ Such freedom in socialising and doing high risk activities gave the adolescents a sense of independence that they desired. Many teenagers regard independence as fun and some even expect a period of freedom without having any responsibilities before they enter adulthood. ${ }^{18}$ In a study among delinquent teenagers in a rehabilitation institution, a majority of them expressed their desire for freedom and they felt irritated when they were restrained from doing things they wished for. ${ }^{19}$

Lack of interest in school appeared to be another factor that encouraged adolescents to hang out with friends and engaged in more enjoyable activities. In fact, academic problems are one of the most common problems faced by school-going teenagers in Malaysia. ${ }^{17}$ Previous studies reported a lack of interest in school, poor academic achievement and dropping out of school as indirect factors towards teenage pregnancy. ${ }^{20-23}$ Since some of the participants expressed various interests in areas other than the mainstream education such as arts, photography, fashion, culinary activities or sports, the education system should have room to allow students to change to the course of their interest without difficulty. Their aspiration to learn is more likely to be maintained when studying the courses they enjoyed.

Curiosity to experiment with new experiences was evidently strong among the participants. They experimented with high-risk behaviours which were culturally and religiously unacceptable and disapproved by their parents. This concurred with a study among delinquent teenagers in a rehabilitation institution that showed about $80 \%$ of them always wanted to experiment with new things which they had never experienced before. ${ }^{19}$ The role of curiosity as a factor for premarital sexual activities and out-of-wedlock pregnancy among teenagers has also been shown in many previous studies.7,13,14,16 Even though the participants placed the blame on their own curiosity, it should be noted that inquisitiveness is an important developmental process for adolescents. Nevertheless, being curious in the presence of bad peer influence, pornography, and substance abuse which causes disinhibition, and the lack of proper sexual and 
Table I: Example of excerpts in socially rela---ted preventive factors.

\begin{tabular}{|c|c|}
\hline Social Factors & Example of Excerpts \\
\hline $\begin{array}{l}\text { Being selective in } \\
\text { choosing friends }\end{array}$ & $\begin{array}{l}\text { "Avoid yourselves from mingling around with bad friends.... that can lead us astray toward bad } \\
\text { things" } \\
\text { "The way we mingle around with friends.... must know how to choose friends". }\end{array}$ \\
\hline $\begin{array}{l}\text { Self-control when with } \\
\text { peers }\end{array}$ & $\begin{array}{l}\text { "Do not overly follow your feelings to try something new till you put your dignity at stake" } \\
\text { "Learn more regarding the restrictions when interacting with boys". }\end{array}$ \\
\hline $\begin{array}{l}\text { Positive engagement } \\
\text { with peers }\end{array}$ & $\begin{array}{l}\text { "Hope that the adolescents out there will use their time studying and not doing wasteful activities } \\
\text { like what I did (with my peers)". }\end{array}$ \\
\hline Be more assertive & $\begin{array}{l}\text { "I had sex with my boyfriend many times. Then I rejected him. Then he asked me out (and I } \\
\text { can't say no)... So (my advice if possible)... if he asked you to go out with him... don't bother } \\
\text { because if just the two of you, something bad might bappen". }\end{array}$ \\
\hline $\begin{array}{l}\text { Selective use of social } \\
\text { media }\end{array}$ & $\begin{array}{l}\text { "If possible, off the Facebook (when interacting with peers). Because friends in it are not real } \\
\text { friends... Reduce using the phone... because there are (pornographic) videos that can be viewed. } \\
\text { After watching them, you feel like you want to try". }\end{array}$ \\
\hline
\end{tabular}

reproductive education; might have collectively led them to engage in premarital sexual activity. 24 Informed teenagers are believed to be much more capable of making wise sexual decisions as they know the risks and consequences of unprotected sex and the responsibilities of their actions. The participants in this study might perceive physical intimacy and sexual intercourse as a way to show their love, care and trust. This finding concurs with other studies in which the participants regarded the sexual relationship as proof of love and trust.8,12,25 Having sexual intercourse without using contraception, as practiced by some of the participants in this study, had also been shown as a way to show their trust. ${ }^{14,25}$ Nonetheless, out-of-wedlock pregnancy is undeniably a taboo within Asian culture, particularly within the Muslim community.

Another factor that could have affected the judgement in adolescents for risky sexual behaviours is the disinhibition caused by substance used. ${ }^{26}$ Under the influence of substance use such as alcohol or drugs, the sexual act could have occurred without full awareness of the victim, as mentioned by one of the participants. This so-called "unconsented" component of the sexual relationship may contribute to negative emotional outcomes and conflict in the abused victim, as documented in previous studies. ${ }^{27,28}$

The lack of attention and loving relationships at home as described by some participants had driven them to desperately find happiness in relationships outside of the home; not surprisingly they would fall for any boy who claimed to love them and wanted to be their boyfriend.7,25,29 These findings suggest the importance of imparting teenagers with the correct understanding of romantic relationship, physical boundaries in relationships and preserving own dignity and virginity until marriage. This could be delivered through sex and reproductive education as well as religious teachings given by parents and teachers. They should also be equipped with skills in decision making and being assertive. As part of sex education, boys should also be taught to respect girls from a young age such that they do not see girls as sex objects but treat their girlfriends with dignity and respect and thus sexual relations become a two-person decision.

Many studies have shown the association between religiosity and premarital sexual activity. Those with poor religious teaching, practice and faith had a tendency to engage in premarital sexual activity.7,9,13,16 In this study, poor religious practice and lack of religious teaching were also mentioned as factors that led to their out-of-wedlock pregnancy. Although religious education is given in school, they still felt it was inadequate and the findings suggested a poor parental role in providing religious teachings and ensuring its practice. However, previous studies have shown that a majority of pregnant or delinquent teenagers admitted to having parents who instilled religious values in them and showed exemplary religious practice.16,19 This was reported by Abdul Samad et al. which demonstrated an insignificant association between parental religious practice and sexual initiation among female teenagers. ${ }^{10}$ The decline of religiosity among teenagers might occur even if they were brought up by religious parents due to other external factors such as peer and media influence, as well as acculturation. Weak religiosity could lead to a liberal attitude towards premarital sex by ignoring religious rules and prohibitions. ${ }^{14,16}$ Nevertheless, the 
importance of religious activities particularly performed by female teenagers could significantly reduce their risk for engaging in premarital sexual activity. ${ }^{10,14,29,30}$ The role of parents in preventing premarital sexual activities among teenagers has been recognized. ${ }^{31}$ A review of studies done in other countries showed that parentteenager connectedness and communication could protect teenagers from engaging in premarital sexual activities and prevent out-of-wedlock pregnancy. ${ }^{15}$ In line with this review, a local study found that teenagers who had parents that understood their problems or were aware of their activities during their free time were unlikely to have premarital sex. ${ }^{3}$ Unfortunately, the participants in our study appeared to have poor relationships with their parents. Similar findings were found by a number of studies that examined parental influence among teenagers who had premarital sexual activities or pregnancy.7,8,12,16

Contrary to these findings, a national study showed an insignificant association between parental control and connectedness with premarital sex. ${ }^{10}$ Lack of attention and time spent by the parents might be due to both of them being preoccupied with working to earn a living. 7,16 The current study also highlights permissive parenting as reported by some of the teenagers, whereas others had parents who were over-controlling. Both types of parenting are believed to represent the extremes of autonomy in teenagers allowed by their parents and these parenting styles seem to have negative impacts on the teenagers. Hamjah et al, reported high level of autonomy given to trusting teenagers to do activities outside their home was noted in more than half of the pregnant Malaysian teenagers. ${ }^{16}$

This finding suggested the role of permissive parenting as a factor for premarital sexual activity among teenagers. Likewise, over-controlling and strict parenting were also found to increase the odds for teenagers to engage in premarital sexual activity. ${ }^{15,29}$ Conflicts between parents might worsen the impact on teenagers who already felt unloved and neglected by parents, as seen in a participant of this study. Similar family conflict and disharmony were also described by pregnant teenagers in other local studies. ${ }^{6,8}$

\section{STUDY STRENGTH AND LIMITATIONS}

This study provides insight into our understanding of pregnant teenagers in the community where out-ofwedlock teenage pregnancy is frowned upon. The plight of these teenagers struggling in the relational issues is a call for help to the service providers and the community. The study was conducted among pregnant teenagers in a shelter home run by the state government's religious authority; hence it is not representative of all out-of-wedlock teenage pregnancies. However, it seems that the relational issues found in this study were not culturally bound. The findings are not necessarily transferable but should be considered according to the local context.

\section{CONCLUSION}

Relational issues with parents, peers and boyfriends are important factors as it could lead to out-of-wedlock pregnancy among adolescents and youths. The storms and stresses of adolescence require parents and community members not to ignore the importance of guiding the teenagers to follow the healthy life path and to avoid pitfalls that would throw them into the dungeon of making the wrong choices in life. A secure and healthy relationship provided by parents may prevent the child from turning to the wrong people for intimacy and comfort. A change in the current education system may be necessary to ensure effective contraception is practiced by the adolescents if abstinence cannot be guaranteed. As building positive relationship with friends, being more assertive and selectively using social media were the highlights of preventive measures in the study, the education system should also empower the teenagers with these qualities.

\section{DISCLOSURE/CONFLICT OF INTEREST STATEMENT}

The authors have no conflict of interest to disclose. 


\section{ACKNOWLEDGMENT}

The authors wish to thank Universiti Kebangsaan Malaysia for funding the research, UKM-GUP-2011328. We would also like to express our gratitude to PERMATApintarTM National Gifted Centre, Universiti Kebangsaan Malaysia and its Director for assisting us throughout the research. We would also like to thank the relevant state religious department, the staff of the selected institution and the participants for their willingness to be involved in this study.

\section{REFERENCES}

1. Organization WH. Preventing early pregnancy and poor reproductive outcomes among adolescents in developing countries: What the evidence says. Geneva: World Health Organization; 2012.

2. Mohd MA, Adibah H, Haliza G. A review of teenage pregnancy research in Malaysia. The Medical journal of Malaysia. 2015;70(4):214-9.

3. Ahmad N, Awaluddin SM, Ismail H, Samad R, NikAbdRashid N. Sexual activity among Malaysian school-going adolescents: what are the risk and protective factors? Asia Pacific Journal of Public Health. 2014;26:44S-52S.

4. Folasayo A, Oluwasegun A, Samsudin S, Saudi S, Osman M, Hamat R. Assessing the knowledge level, attitudes, risky behaviors and preventive practices on sexually transmitted diseases among university students as future healthcare providers in the central zone of Malaysia: a cross-sectional study. International journal of environmental research and public health. 2017 Feb;14(2):159.

5. Hamid SR, Ismail K, Saad S, Ibrahim MB, Mansur N. Are the Malaysian Adolescents' Behavior At-Stake?. Mediterranean Journal of Social Sciences. 2015 May 1;6(2 S5):328.

6. Jamaluddin Z. Premarital pregnancy and abortion among adolescent. Adv Nat Appl Sci. 2013;7 (4):366-8.

7. Alavi K, Nen S, Ibrahim F, Akhir NM, Mohamad MS, Nordin NM. Hamil luar nikah dalam kalangan remaja. e-BANGI. 2012;7(1):13140 .
8. Ghadur SA, Kadir NByA. HUBUNGAN ROMANTIK DAN REMAJA HAMIL LUAR NIKAH DI PUSAT PEMULIHAN (Romantic

Relationships and Unwed Pregnancy of Adolescence Residing at Rehabilitation Center). e -Bangi. 2017;6(1).

9. Awaluddin SM, Ahmad NA, Saleh NM, Aris T, Kasim NM, Sapri NAM, et al. Prevalence of sexual activity in older Malaysian adolescents and associated factors. Journal of Public Health Aspects. 2015;2(1):1.

10. Abdul Samad S, Hairi NN, Ismail M. Role of individual, family, and peers in sexual initiation among late adolescents attending institutions of higher learning in Malaysia. Asia Pacific Journal of Public Health. 2016;28(4):313-24.

11. Farid NDN, Che'Rus S, Dahlui M, Al-Sadat N, Aziz NA, editors. Predictors of sexual risk behaviour among adolescents from welfare institutions in Malaysia: a cross sectional study. BMC public health; 2014: BioMed Central.

12. Farid NDN, Che'Rus S, Dahlui M, Al-Sadat N. Determinants of sexual intercourse initiation among incarcerated adolescents: a mixed-method study. Singapore Med J. 2013;54(12):695-701.

13. Nik Farid N, Dahlui M, Che'Rus S, Aziz N, AlSadat N. Early Sexual Initiation among Malaysian Adolescents in Welfare Institutions: A Qualitative Study. Arts Social Sci J. 2015;6 (129):2.

14. Wong LP. An exploration of knowledge, attitudes and behaviours of young multiethnic Muslim-majority society in Malaysia in relation to reproductive and premarital sexual practices. BMC public health. 2012;12(1):865.

15. Markham CM, Lormand D, Gloppen KM, Peskin MF, Flores B, Low B, et al. Connectedness as a predictor of sexual and reproductive health outcomes for youth. Journal of adolescent health. 2010;46(3):S23-S41.

16. Hamjah SH, Samuri MAA, Rasit RM, Sham FM, Kusrin ZM, Ismail Z, et al. Factors relating to premarital pregnancy amongst Muslim adolescents in Malaysia. Research Journal of Medical Sciences. 2012;6(6):266-71. 
17. Hashim IHM. Stress, Coping and Social Supports in Adolescent Years. Kajian Malaysia. 2007;25(1):97-115.

18. Barker ET, Galambos NL. Adolescents' implicit theories of maturity: Ages of adulthood, freedom, and fun. Journal of Adolescent Research. 2005;20(5):557-76.

19. Sharif Z, Mohamad Roslan N. Faktor-faktor yang mempengaruhi remaja terlibat dalam masalah sosial di Sekolah Tunas Bakti, Sungai Lereh, Melaka. Journal of Education Psychology \& Counseling. 2011;1(7):115-40.

20. Omar K, Hasim S, Muhammad NA, Jaffar A, Hashim SM, Siraj HH. Adolescent pregnancy outcomes and risk factors in Malaysia. International Journal of Gynecology \& Obstetrics. 2010;111(3):220-3.

21. Tan P, Tohid H, Su X, Tan K, Azimah M, Khairani O. A study on pregnant adolescents residing in a government home: common characteristics and their views on the pregnancy. Malaysian family physician: the official journal of the Academy of Family Physicians of Malaysia. 2012;7(1):11.

22. Parkes A, Waylen A, Sayal K, Heron J, Henderson M, Wight D, et al. Which behavioral, emotional and school problems in middlechildhood predict early sexual behavior? Journal of youth and adolescence. 2014;43(4):507-27.

23. Panova O, Kulikov A, Berchtold A, Suris J. Factors associated with unwanted pregnancy among adolescents in Russia. Journal of pediatric and adolescent gynecology. 2016;29(5):501-5.

24. Brown JD, Keller S, Stern S. Sex, sexuality, sexting, and sexed: Adolescents and the media. The prevention researcher. 2009;16(4):12-7.

25. Ng CJ, Kamal S. Bridging the gap between adolescent sexuality and HIV risk: the urban Malaysian perspective. Singapore medical journal. 2006;47(6):482.

26. Sulaiman AH, Said MA, Das S. Substance use, sexual intercourse, and condom nonuse among depressed adolescents and young adults: scientific views. Journal of Adolescent Health. 2012;50(6):654.

27. Wahab S, Rahman A, Nazri F, Hashim SM, Razali S. Intrafamilial Sexual Abuse in an Asian
Society: Understanding the Victim's Internal Conflicts. International Medical Journal. 2013;20 (2).

28. Wahab S, Tan SMK, Marimuthu S, Razali R, Muhamad NA. Young female survivors of sexual abuse in $\mathrm{M}$ alaysia and depression: What factors are associated with better outcome? Asia-Pacific Psychiatry. 2013;5:95-102.

29. Wong LP. Qualitative inquiry into premarital sexual behaviours and contraceptive use among multiethnic young women: implications for education and future research. PloS one. 2012;7 (12):e51745.

30. Muhammad NA, Shamsuddin K, Sulaiman Z, Amin RM, Omar K. Role of Religion in Preventing Youth Sexual Activity in Malaysia: A Mixed Methods Study. Journal of religion and health. 2017;56(6):1916-29.

31. Sutan R, Mahat AN. Parenting Skills Determinant in Preventing Adolescents' Sexual Health Risk Behavior. Open Journal of Preventive Medicine. 2017;7(01):1. 